\section{Gategory}

Metal-Catalyzed

Asymmetric

Synthesis and

Stereoselective

Reactions

\section{Key words}

rhenium

tetrahydropyrans

Prins cyclization

SYNFACTuth

\title{
Stereocontrolled Synthesis of Highly Substituted Tetrahydropyrans
}

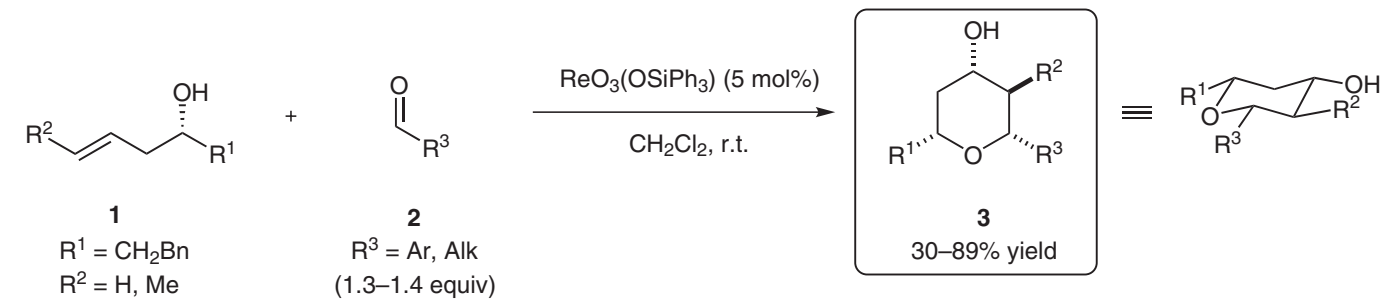

\section{Selected examples:}<smiles>OC1CC(CBr)OC(CBr)C1</smiles>

4

$63 \%$ yield
d.r. $=1.9: 1$

$\mathrm{OH}$<smiles>COc1cc([C@H]2O[C@H](Cc3ccccc3)C[C@H](O)[C@H]2C)c(OP(=O)(O)O)c(OC)c1C</smiles>

$83 \%$ yield<smiles>CC(C)C1CC(O)CC(CBr)O1</smiles>

$\mathrm{OH}$<smiles>COc1ccccc1[C@@H]1O[C@H](Cc2ccccc2)C[C@H](C)[C@H]1O</smiles>

$\stackrel{9}{84 \% \text { yield }}$<smiles>COc1ccc(C2CC(O)CC(Cc3ccccc3)O2)cc1</smiles><smiles>O[C@H]1[CH][C@H](c2ccc(F)cc2)O[C@H](CBr)C1</smiles>

10

$97 \%$ ee (with $1=99 \%$ ee)

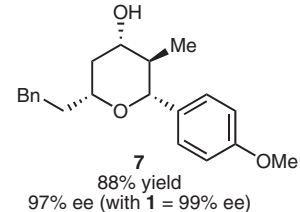
$97 \%$ ee (with $1=99 \%$ ee)

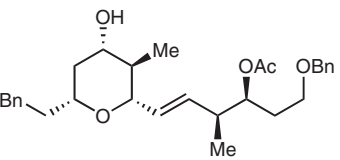
11
$62 \%$ yield

Proposed mechanism:

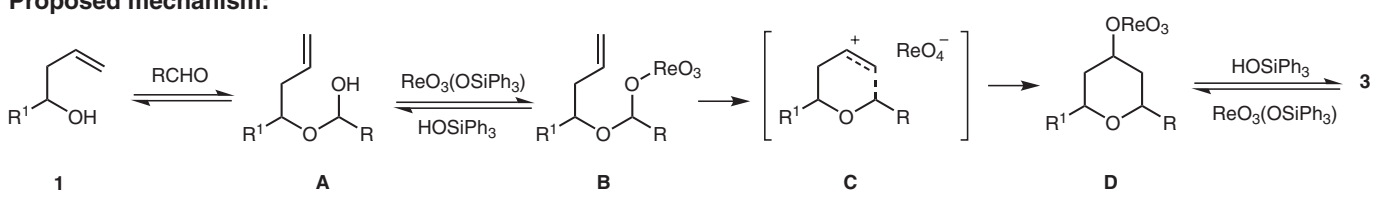

Significance: $A \operatorname{Re}(\mathrm{VII})$ complex catalyzed the highly selective condensation of easily accessible starting materials using a very mild and simple protocol to give densely functionalized tetrahydropyrans 3 (THP). Aromatic aldehyde partners 2 give a single diastereomer where all substituents are equatorially oriented. Whereas aliphatic aldehydes give diastereomeric mixtures (4 and $\mathbf{5}$ ), alkenyl aldehydes provide an alternative, as illustrated by complex THP 11. Achieving high atom-efficiency, the catalytic Prins cyclization reported improves previous protocols using excess acid (the conjugate base moiety is generally incorporated into the THP at the end of the reaction).

SYNFACTS Contributors: Mark Lautens, Frédéric Ménard Synfacts 2009, 1, 0052-0052 Published online: 18.12.2008 Dol: 10.1055/s-0028-1087404; Reg-No: L15808SF
Comment: Both $\mathrm{ReO}_{3}(\mathrm{OH})$ and $\mathrm{Re}_{2} \mathrm{O}_{7}$ were shown to be effective catalysts to mediate the transformation. The authors were inspired by seminal work on allylic alcohol isomerization done by Osborn and co-workers (Angew. Chem. Int. Ed. 1997, 36, 976), as well as later investigations done by Grubbs and co-workers (J. Am. Chem. Soc. 2005, 127, 2842). These early studies invoked a cationic intermediate suggesting that intermediate $\mathbf{C}$ might be a viable species in the above process. A potential limitation of the reaction is seen with aliphatic aldehydes $\mathbf{2}$, which are prone to form side-products arising from competing oxonia-Cope rearrangements under these conditions. 